\title{
Preharvest Application of a Boscalid and Pyraclostrobin Mixture to Control Postharvest Gray Mold and Blue Mold in Apples
}

\author{
C. L. Xiao and R. J. Boal, Department of Plant Pathology, Washington State University, Tree Fruit Research and \\ Extension Center, 1100 N. Western Avenue, Wenatchee, WA 98801
}

\begin{abstract}
Xiao, C. L., and Boal, R. J. 2009. Preharvest application of a boscalid and pyraclostrobin mixture to control postharvest gray mold and blue mold in apples. Plant Dis. 93:185-189.

After harvest, apples (Malus $\times$ domestica) may be kept in cold storage for up to 12 months prior to packing. Gray mold caused by Botrytis cinerea and blue mold caused by Penicillium expansum are common postharvest fruit rot diseases affecting apples and are controlled commonly by applications of fungicides after harvest. To search for an alternative strategy, Pristine (a premixed formulation of boscalid and pyraclostrobin) as a preharvest treatment was evaluated for control of postharvest gray mold and blue mold in cultivars Fuji and Red Delicious apples during 2004 to 2006. Pristine ( $0.36 \mathrm{~g}$ per liter of water) was applied 1, 7, or 14 days before harvest. For comparison, thiram ( $2.04 \mathrm{~g}$ per liter of water) was applied 7 days before harvest and ziram ( $2.4 \mathrm{~g}$ per liter of water) was applied 14 days before harvest, to Fuji and Red Delicious, respectively. Fruit were harvested at commercial maturity, wounded with a finishing nail head, inoculated with conidial suspensions of either $B$. cinerea or $P$. expansum, stored in air at $0^{\circ} \mathrm{C}$, and evaluated for decay after 8 or 12 weeks. In 2004 and 2005, Pristine was equally effective when applied to Fuji 1 or 7 days before harvest, reducing gray mold incidence by 93 to $99 \%$ and blue mold incidence by 78 to $94 \%$ compared with the nontreated control. Thiram reduced gray mold incidence by 38 to $85 \%$. Thiram reduced blue mold incidence by $22 \%$ in 2004 but not in 2005 . On Red Delicious, Pristine was equally effective when applied 7 or 14 days before harvest and reduced gray mold incidence by 69 to $85 \%$ and blue mold incidence by 41 to $70 \%$. Ziram applied 2 weeks before harvest reduced gray mold incidence by 97 and $94 \%$ in 2005 and 2006, respectively, but it did not reduce blue mold incidence. The results indicate that Pristine applied within 2 weeks before harvest may be an effective alternative to postharvest fungicides for control of postharvest gray mold and blue mold in Fuji and Red Delicious apples.
\end{abstract}

Apple fruit are hand harvested and placed into wooden or plastic bins (approximately $400 \mathrm{~kg}$ of fruit per bin), and bins are then transported to storage and packing facilities. Fruit are stored in field bins in air for short-term storage and in controlled atmosphere (1 to $2 \% \mathrm{O}_{2}$ and $0.5 \% \mathrm{CO}_{2}$ ) at -1 to $3^{\circ} \mathrm{C}(13)$, depending on cultivar, for long-term storage until packing. Fruit may remain in field bins for up to 10 to 12 months, during which time fruit rot diseases develop, leading to economic losses.

Gray mold caused by Botrytis cinerea and blue mold caused by Penicillium expansum are common postharvest fruit rot diseases of apple worldwide (24). In a recent survey of postharvest diseases of apples conducted in Washington State, gray mold and blue mold accounted for 28 and $32 \%$ of the decayed fruit (11). Punctures, bruises, or any physical damage on the fruit peel are the main avenue for $B$.

Corresponding author: C. L. Xiao

E-mail: clxiao@wsu.edu

Accepted for publication 29 October 2008.

doi:10.1094/PDIS-93-2-0185

(C) 2009 The American Phytopathological Society cinerea and $P$. expansum to infect apple fruit $(16,17)$. Thus, protecting wounds that are created at harvest and during postharvest handling from infections by $B$. cinerea and $P$. expansum is essential to the control of gray mold and blue mold in apples.

Chemical control remains the main measure for control of postharvest diseases of pome fruits (1). Commercially, apple fruit may be drenched with diphenylamine (DPA; an antioxidant) in combination with a fungicide prior to storage to control superficial scald (a physiological disorder of the fruit peel) and postharvest diseases, respectively (14). Currently there are four fungicides available for postharvest use on apples in the United States: captan, thiabendazole (TBZ), fludioxonil, and pyrimethanil. Captan is not commonly used by fruit packers. Prior to 2005, TBZ was the most commonly used postharvest fungicide on apples, but resistance of $P$. expansum to TBZ often results in the failure of blue mold control $(7,12)$. Fludioxonil and pyrimethanil were registered in 2004 in the United States for postharvest use on apples and pears. The two new fungicides are effective in controlling gray mold and blue mold $(7,12,20)$.

New alternatives to DPA drench for scald control include treatment with 1methylcyclopropene (1-MCP), an inhibitor of ethylene action (5), or a fog treatment of closed apple-storage rooms with micronized droplets of DPA (4). 1-MCP inhibits the apple fruit ripening process, thus retaining fruit firmness (8), and also controls superficial scald of apple fruit (9). Because 1-MCP is applied as a vapor in storage rooms, some apple packers who apply 1-MCP have eliminated drench treatments with DPA and fungicides. Fogging closed fruit-storage rooms with DPA in combination with fungicides could be a promising alternative to traditional DPA and fungicide drench practice (4), but this technology has not been fully approved for commercial use in the United States. Eliminating a postharvest drench with fungicides may result in increased losses of apple fruit due to postharvest diseases during storage (11). Thus, alternatives to postharvest drenches with fungicides are needed for control of postharvest diseases in fruit that are treated with $1-\mathrm{MCP}$ or micronized DPA without postharvest fungicides.

Use of preharvest fungicides during the growing season and particularly near harvest is a potential strategy for control of postharvest diseases. Thiram and ziram have been used as preharvest treatments applied near harvest for control of bull'seye rot caused by Neofabraea spp. and other postharvest diseases of apples and pears in the U.S. Pacific Northwest $(21,25)$. However, thiram is no longer registered for apples and pears, and residues of ziram on the fruit may cause skin irritation to fruit pickers. Alternatives to these older fungicides are needed for control of postharvest gray mold and blue mold.

Pristine, a premixed formulation of boscalid and pyraclostrobin, was registered in the United States in 2005 for preharvest uses on pome fruits. Boscalid is a new broad-spectrum fungicide belonging to the carboxamide class, and pyraclostrobin belongs to the quinine outside inhibitor (QoI) class. Pristine has been shown to be effective in controlling a wide range of fungal diseases on different crops (2). In apple orchards, Pristine can be used to control powdery mildew, scab, sooty blotch, flyspeck, and summer fruit rots $(15,18,27)$.

The objective of this study was to evaluate strategies for using the new fungicide Pristine as a preharvest treatment for controlling gray mold and blue mold in stored apples.

Plant Disease / February 2009

185 


\section{MATERIALS AND METHODS}

The pathogens. One isolate each of $P$. expansum (CLX1499) and $B$. cinerea (CLX193), both isolated from decayed apple fruit, were used in this study. The isolate of $P$. expansum was stored as a conidial suspension and the isolate of $B$. cinerea as mycelial plugs in $15 \%$ glycerol $(1: 1, \mathrm{vol} / \mathrm{vol})$ at $-80^{\circ} \mathrm{C}$.

To produce inoculum for fruit inoculation, conidial suspensions of $P$. expansum were made from cultures grown for 7 to 10 days on potato dextrose agar (PDA; Difco Laboratories, Detroit, MI) in the dark at $20^{\circ} \mathrm{C}$. Spore density was adjusted to approximately $6 \times 10^{3}$ conidia/ml. Conidial suspensions of $B$. cinerea were made from cultures grown for approximately 3 weeks on PDA at $20^{\circ} \mathrm{C}$ with 12-h light/12-h dark. Spore density was adjusted to $3 \times 10^{4}$ conidia/ml.

Experiments on Fuji apple. Experiments were conducted in a research orchard of Fuji apple trees planted in 1991 near Orondo, WA. Trees were under-tree irrigated. Insects and weeds were controlled following the recommendations commonly used for commercial apple production (21). No fungicides were used in this orchard during the course of the experiment. Powdery mildew was evident on leaves early in the growing seasons, but there were no disease symptoms on fruit at harvest.

In 2004 , Pristine $(0.36 \mathrm{~g}$ per liter of water) and thiram (2.04 g per liter of water) were applied 7 days before harvest, and control trees received no treatment. In 2005, Pristine was applied 7 days or 1 day before harvest, and thiram was applied 7 days before harvest. Fungicide treatments were applied to runoff with a powered handgun sprayer. Each treatment was applied to four 1- to 2-tree replicates arranged in a randomized complete block design. After fungicide applications, one rain event occurred one day before harvest in 2004, and no rain occurred before harvest in 2005. Fruit were harvested on 18 October 2004 and 20 October 2005, at commercial maturity. After harvest, fruit were immediately transported into the laboratory. There were 20 fruit per replicate for each postharvest treatment. Each fruit was wounded to a depth of $3 \mathrm{~mm}$ with a 4-mm-diameter finishing nail head and subsequently inoculated by placing $20 \mu \mathrm{l}$ of conidial suspensions of $P$. expansum (6 $\times 10^{3}$ spores $\left./ \mathrm{ml}\right)$ or $B$. cinerea $\left(3 \times 10^{4}\right.$ spores/ml) with a pipette into each wound.
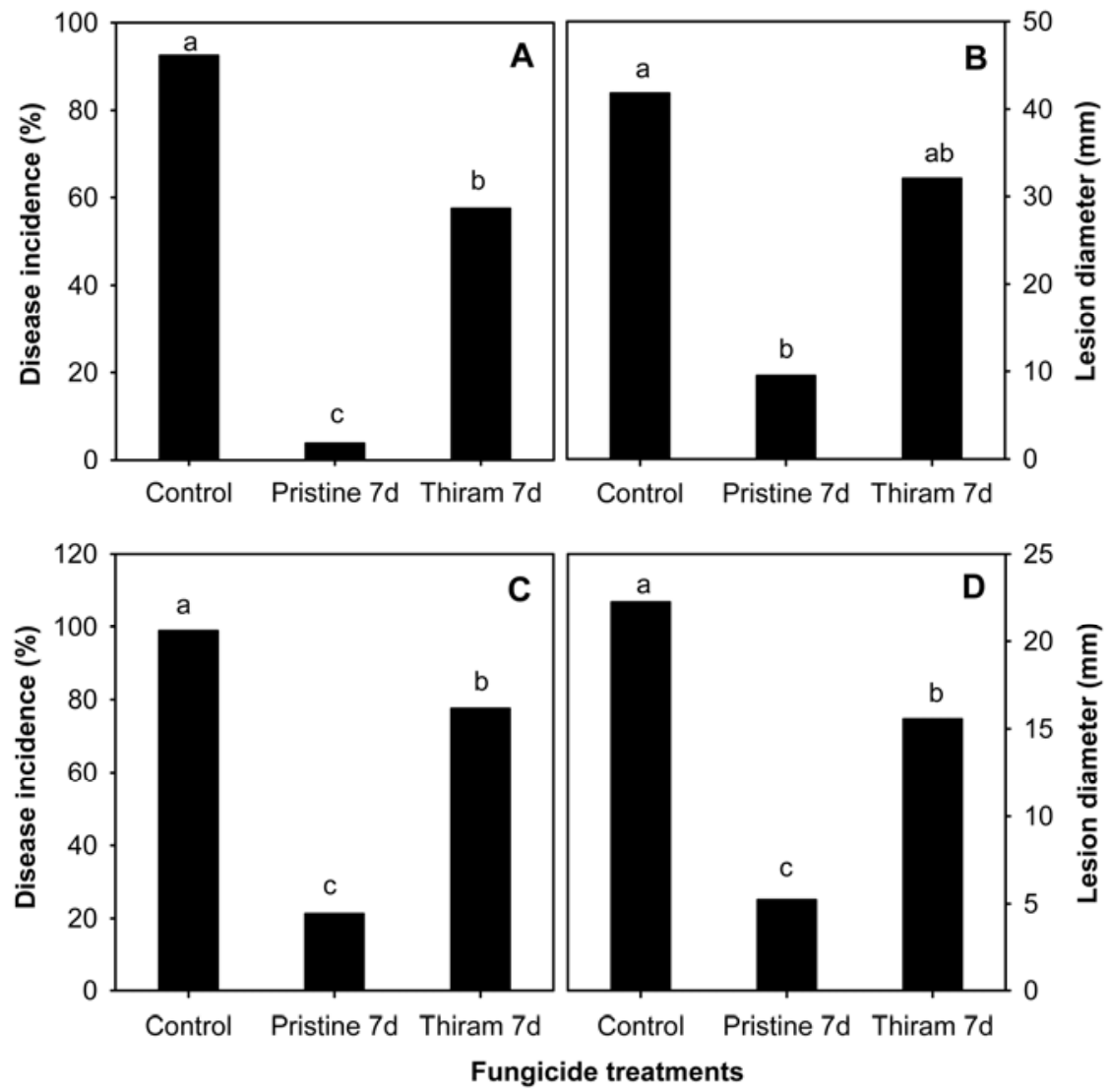

Fig. 1. Effectiveness of Pristine, a premixed formulation of boscalid and pyraclostrobin, and thiram applied 7 days before harvest in controlling gray mold (A and B) and blue mold (C and D) in stored Fuji apples in 2004. Fruit were wounded and inoculated with conidial suspensions of Botrytis cinerea or Penicillium expansum immediately after harvest and then stored at $0^{\circ} \mathrm{C}$ for 12 weeks, at which time decay was evaluated. Average lesion size within each replicate of each treatment was calculated among the decayed fruit only. Columns marked with the same letter are not significantly different at $k$-ratio $=$ $100(P=0.05)$ according to the Waller-Duncan $k$-ratio $t$ test.
Fruit were placed on sterilized fiberboard fruit trays wrapped in perforated polyethylene bags and stored in cardboard boxes in air at $0^{\circ} \mathrm{C}$ for 12 weeks in 2004-05 and 10 weeks in 2005-06, at which time lesion diameters at inoculation sites on the fruit were measured and percentage of the fruit with gray mold or blue mold was calculated.

Experiments on Red Delicious apple. Red Delicious apple trees planted in 1996 in a research orchard in Wenatchee, WA were used in this study. Trees were undertree irrigated. Insects and weeds were controlled following the recommendations commonly used for commercial apple production (21). One application each of triflumizole (Procure) and trifloxystrobin (Flint) in 2005 and one application each of thiophanate-methyl (Topsin $\mathrm{M}$ ) and triflumizole in 2006 were made during late March and April to control powdery mildew. No fungicides were used in this orchard after April.

In both 2005 and 2006, Pristine (0.36 g per liter of water) was applied 14 or 7 days before harvest. Ziram ( $2.4 \mathrm{~g}$ per liter of water) was applied 7 days before harvest, and control trees received no treatment. Fungicide treatments were applied to runoff with a powered handgun sprayer. Each treatment was applied to four 1- to 2-tree replicates arranged in a randomized complete block design. After fungicide applications, no rain occurred before harvest in both years. Fruit were harvested at commercial maturity on 29 September in both 2005 and 2006. After harvest, fruit were immediately transported into the laboratory. There were 20 fruit per replicate for each postharvest treatment. Fruit were wounded and inoculated in the same manner as described above. Fruit were stored in cardboard boxes in air at $0^{\circ} \mathrm{C}$ for 8 weeks in 2005 and 10 weeks in 2006, at which time lesion diameters at inoculation sites on the fruit were measured and percentage of the fruit with gray mold or blue mold was calculated.

Data analysis. Disease incidence was expressed as percentages of decayed fruit in the total inoculated fruit in each replicate of each treatment. Disease incidence data were transformed with arcsine-squareroot transformation prior to statistical analysis. Average lesion size within each replicate of each treatment was calculated among the decayed fruit only. Disease incidence and lesion size were analyzed by analysis of variance using PROC GLM of SAS (version 9.1, SAS Institute, Cary, NC), and means were separated by the Waller-Duncan $k$-ratio $t$ test at $k$-ratio $=$ $100(P=0.05)$.

\section{RESULTS}

In the experiment conducted on Fuji in 2004, Pristine reduced gray mold incidence by $96 \%$ and blue mold incidence by $78 \%$ in comparison with the nontreated 
control (Fig. 1). Thiram reduced gray mold incidence by $38 \%$ and blue mold incidence by $22 \%$ compared with the nontreated control, but it was significantly less effective than Pristine in reducing incidence of gray mold and blue mold. Among the decayed fruit, lesion sizes on decayed fruit from Pristine treatment were significantly smaller than those on fruit treated with thiram (Fig. 1).

On Fuji in 2005, Pristine applied at 1 or 7 days before harvest reduced gray mold incidence by 93 to $99 \%$ and blue mold incidence by 85 to $94 \%$ compared with the nontreated control (Fig. 2). Thiram reduced gray mold incidence by $85 \%$ but not blue mold incidence in comparison with the nontreated control. Except for the effects of Pristine applied at 7 days before harvest on lesion size of gray mold, lesion sizes were significantly smaller on the fruit treated with Pristine than on those treated with thiram, which did not reduce lesion sizes on decayed fruit compared with the nontreated control.

In the experiments conducted on Red Delicious apples in 2005 and 2006, Pristine applied at 7 or 14 days before harvest reduced gray mold incidence by 69 to $79 \%$ in 2005 and 83 to $85 \%$ in 2006 and blue mold incidence by 69 to $70 \%$ in 2005 and 41 to $46 \%$ in 2006 , in comparison with the nontreated control (Figs. 3 and 4). Except for the effects of Pristine applied at 7 days on lesion size of gray mold, lesion sizes on the decayed fruit treated with Pristine were significantly smaller than those on fruit not treated with fungicides. Ziram applied at 2 weeks before harvest significantly reduced gray mold incidence by 97 and $94 \%$ in 2005 and 2006, respectively. Ziram did not reduce blue mold incidence, although it reduced blue mold lesion size compared with the nontreated control. However, the magnitude of reduction in lesion size was small (Figs. 3 and 4).

\section{DISCUSSION}

In this study, we reported the use of the new fungicide Pristine as a preharvest treatment for controlling postharvest gray mold and blue mold in apples. According to the U.S. Environmental Protection Agency classification, Pristine is considered a reduced-risk fungicide, which possesses a low risk to humans and the environment (26). As old fungicides, such as benomyl and thiram, have been or may be removed in the near future from commercial use, the new reduced-risk fungicide Pristine can serve as an alternative to these old fungicides for control of postharvest gray mold and blue mold of apple. 1-MCP has been commonly used to treat apple fruit in cold storage rooms to retain fruit quality and control superficial scald $(8,9)$. When 1-MCP is used to treat apple fruit, the fruit may not be drenched with postharvest fungicides prior to storage, leading to potential economic losses resulting from postharvest diseases in storage. Using preharvest fungicides, such as Pristine, as a preharvest treatment near harvest could also serve as an alternative to postharvest fungicide drenches for control of gray mold and blue mold.

However, preharvest application of Pristine may not be as effective as a postharvest drench treatment with either fludioxonil or pyrimethanil for controlling gray mold and blue mold. For example, virtually no decay developed on apple fruit that were wounded and inoculated with $B$. cinerea or $P$. expansum and treated with postharvest fungicide fludioxonil or pyrimethanil at recommended label rates $(7,12,20)$. In our study, a preharvest Pristine treatment may only reduce blue mold incidence by 41 to $46 \%$ compared with the nontreated control, depending on cultivar and year. Our results suggest that a postharvest drench with either fludioxonil or pyrimethanil may be a better choice than preharvest Pristine for control of gray mold and blue mold for fruit from an orchard with a known history of high incidence of these two diseases. However, there are concerns about potential contamination of apple fruit by food-borne pathogens during postharvest drenching as well as the buildup of apple pathogens in the recirculating drenches. The fruit packing industry would prefer to move away from DPA and fungicide drenches if alternatives are available. As 1-MCP or foggable DPA is being adopted by the fruit industry, the new strategy for decay control we documented in this study could be a viable option.

No research has been done to describe residue levels and distribution and persistence of boscalid and pyraclostrobin in apple fruit. Nevertheless, in this study, the effectiveness of Pristine in controlling gray mold and blue mold was consistently better on Fuji than that on Red Delicious. The exact factors responsible for these differences are unknown. Differences in fruit cuticles between the two apple cultivars and environmental conditions after fungicide applications in the field may affect residue levels on/in the fruit. Red Delicious apple fruit have thicker cuticles than Fuji apple fruit. The differences in cuticles
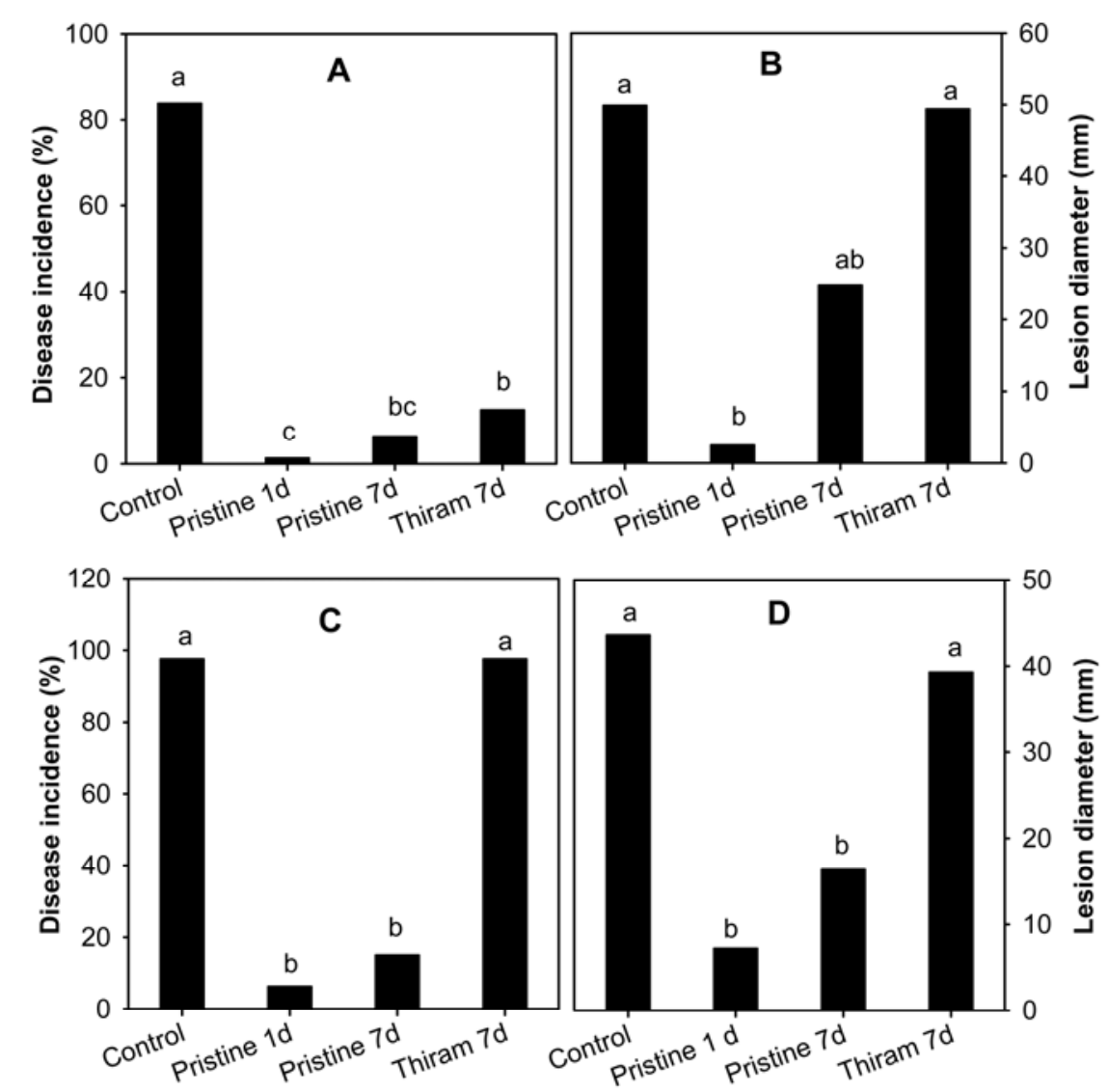

\section{Fungicide treatments}

Fig. 2. Effectiveness of Pristine, a premixed formulation of boscalid and pyraclostrobin, applied either 1 or 7 days before harvest and thiram applied 7 days before harvest in controlling gray mold (A and $\mathbf{B}$ ) and blue mold (C and D) in stored Fuji apples in 2005. Fruit were wounded and inoculated with conidial suspensions of Botrytis cinerea or Penicillium expansum immediately after harvest and then stored at $0^{\circ} \mathrm{C}$ for 10 weeks, at which time decay was evaluated. Average lesion size within each replicate of each treatment was calculated among the decayed fruit only. Columns marked with the same letter are not significantly different at $k$-ratio $=100(P=0.05)$ according to the Waller-Duncan $k$-ratio $t$ test. 

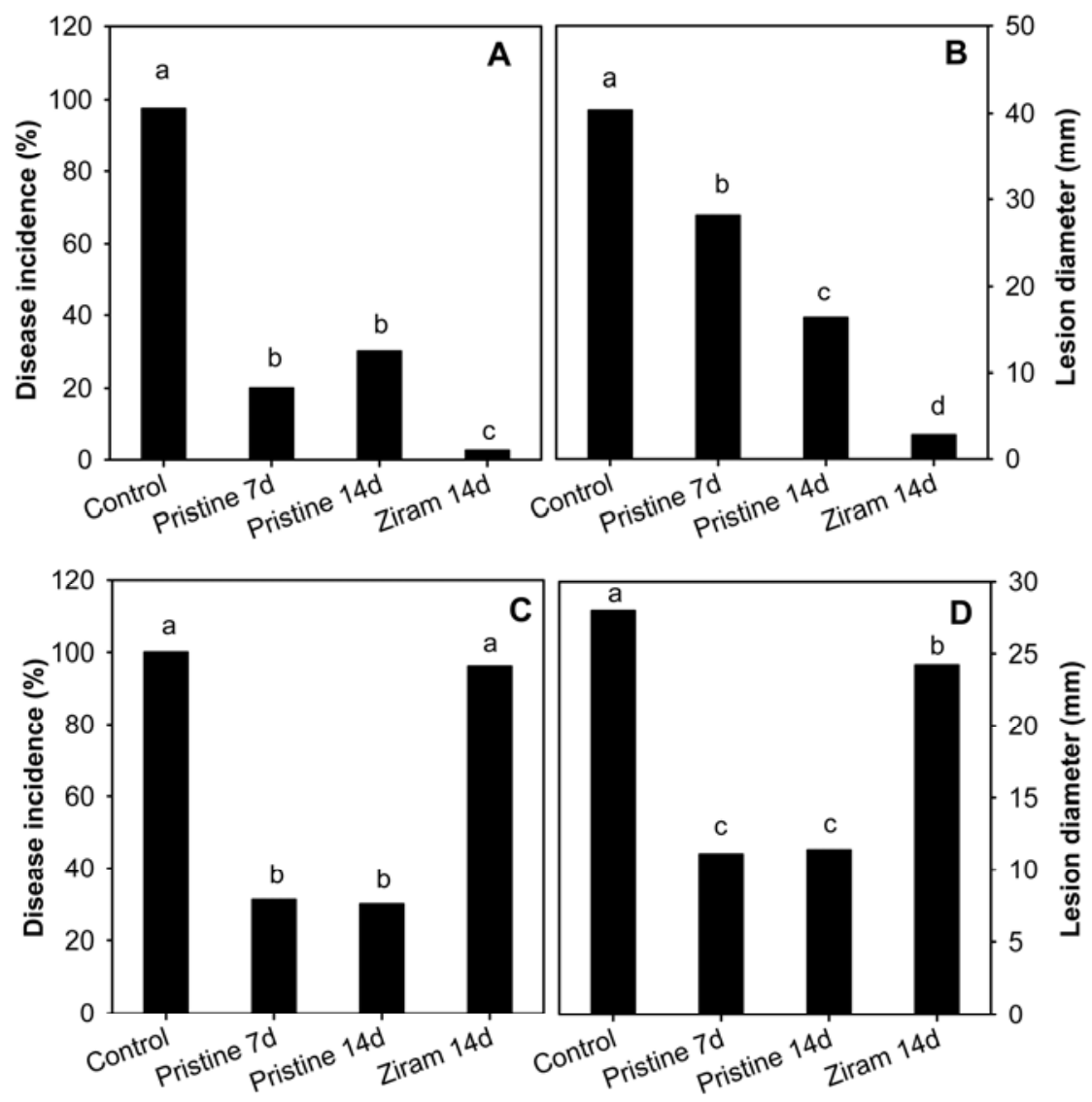

Fungicide treatments

Fig. 3. Effectiveness of Pristine, a premixed formulation of boscalid and pyraclostrobin, applied either 7 or 14 days before harvest and ziram applied 14 days before harvest in controlling gray mold (A and B) and blue mold (C and D) in stored Red Delicious apples in 2005. Fruit were wounded and inoculated with conidial suspensions of Botrytis cinerea or Penicillium expansum immediately after harvest and then stored at $0^{\circ} \mathrm{C}$ for 8 weeks, at which time decay was evaluated. Average lesion size within each replicate of each treatment was calculated among the decayed fruit only. Columns marked with the same letter are not significantly different at $k$-ratio $=100(P=0.05)$ according to the Waller-Duncan $k$ ratio $t$ test.

may affect transcuticular movement of fungicides (22). In central Washington, Red Delicious apples are harvested from mid-September to early October, whereas Fuji apples are harvested during mid-late October. The temperatures at harvest of Fuji are generally lower than those at harvest of Red Delicious. Temperature and/or other environmental factors may affect the uptake of fungicides by apple fruit, penetration of fungicides into the fruit cuticles, and fate of fungicide residues on/in the fruit. In a preliminary study on Fuji apples, when Fuji fruit were treated with Pristine at 7 days before harvest, residual activity of Pristine in apple fruit was still evident after the fruit had been subjected to packing practices (washing, brushing, etc.) 5 months after harvest, indicating Pristine can move into the fruit cuticles or flesh to some extent (C. L. Xiao, unpublished). Cultivar differences in susceptibility to gray mold and blue mold may also contribute to the differences in effectiveness of Pristine on these two cultivars (23).

Ziram is a broad-spectrum multi-site mode-of-action fungicide. In our study, ziram was highly effective in controlling gray mold but not blue mold. Ziram was applied 14 days before harvest following its label for apple. The residue of ziram on/in apple fruit at harvest is likely affected by environmental conditions from its application to fruit harvest. $P$. expansum may be less sensitive to ziram than $B$. cinerea, resulting in lack of control of blue mold by ziram. In other words, a higher level of ziram residue on/in the fruit may be needed for control of blue mold than that for control of gray mold.

The beneficial effects of a preharvest fungicide treatment for control of postharvest diseases of apple can be viewed from three different aspects. First, fungicides may reduce inoculum of decay pathogens on the surface of the fruit. Second, the residue of fungicides on/in the fruit may be able to protect wounds that are created at harvest from infection by decay-causing pathogens such as B. cinerea and $P$. expansum as we documented in this study. Third, fungicides may also be effective for controlling latent fungal infections that lead to fruit rots in storage, such as Sphaeropsis rot caused by Sphaeropsis pyriputrescens, which is another important postharvest disease of apples in Washington State (11). In this study, we did not examine the first component of fungicide effectiveness. Based on the results in this study, we speculate that Pristine could also reduce inoculum levels of $B$. cinerea and $P$. expansum on the surface of apple fruit. A field study indicated that Pristine applied 7 days before harvest also was effective for controlling Sphaeropsis rot (C. L. Xiao, unpublished). Taken together, these results suggest that when Pristine is used as a preharvest treatment, it can be an effective alternative to old fungicides for control of major postharvest diseases of apples grown in Washington State.

Research conducted in Canada indicated that cyprodinil is effective for controlling gray mold of apple when applied before harvest (19). However, cyprodinil has a 72day preharvest spray interval when it is used on apple in the United States. The long preharvest spray interval of cyprodinil limits its use as a preharvest treatment for control of postharvest diseases. Pristine has a 0-day preharvest interval when it is used on apple in the United States (2). A short preharvest spray interval of Pristine offers the flexibility to growers so they can apply the treatment anytime within 2 weeks before harvest.

Although Pristine has two active ingredients belonging to two different classes of chemistries, resistance to boscalid, pyraclostrobin, or Pristine has been reported in Alternaria alternata from pistachio in California (3), indicating the existence of risk in development of resistance to Pristine in fungal pathogens. Resistance to Pristine in A. alternata from pistachio is believed to be multi-drug resistance (3). Pyraclostrobin is a QoI fungicide, and other QoI fungicides also are commonly used in apple orchards for control of powdery mildew, scab, and other diseases (21). Resistance to QoI fungicides has been reported in fungal pathogens (10). B. cinerea and $P$. expansum are high-risk pathogens in the development of fungicide resistance because their short life cycles and prolific spore production capabilities give them the potential to develop fungicide resistance rapidly (6). Because some other QoI fungicides may also be used during apple-growing season for control of powdery mildew and scab, we recommend that for resistance management, applications of QoI fungicides should be limited to not more than four applications per applegrowing season, including one application of Pristine applied as a preharvest treatment near harvest for control of postharvest gray mold and blue mold.

\section{ACKNOWLEDGMENTS}

This research was supported in part by the Washington Tree Fruit Research Commission. This manuscript is Plant Pathology New Series 0490, Department of Plant Pathology, College of Agricul- 

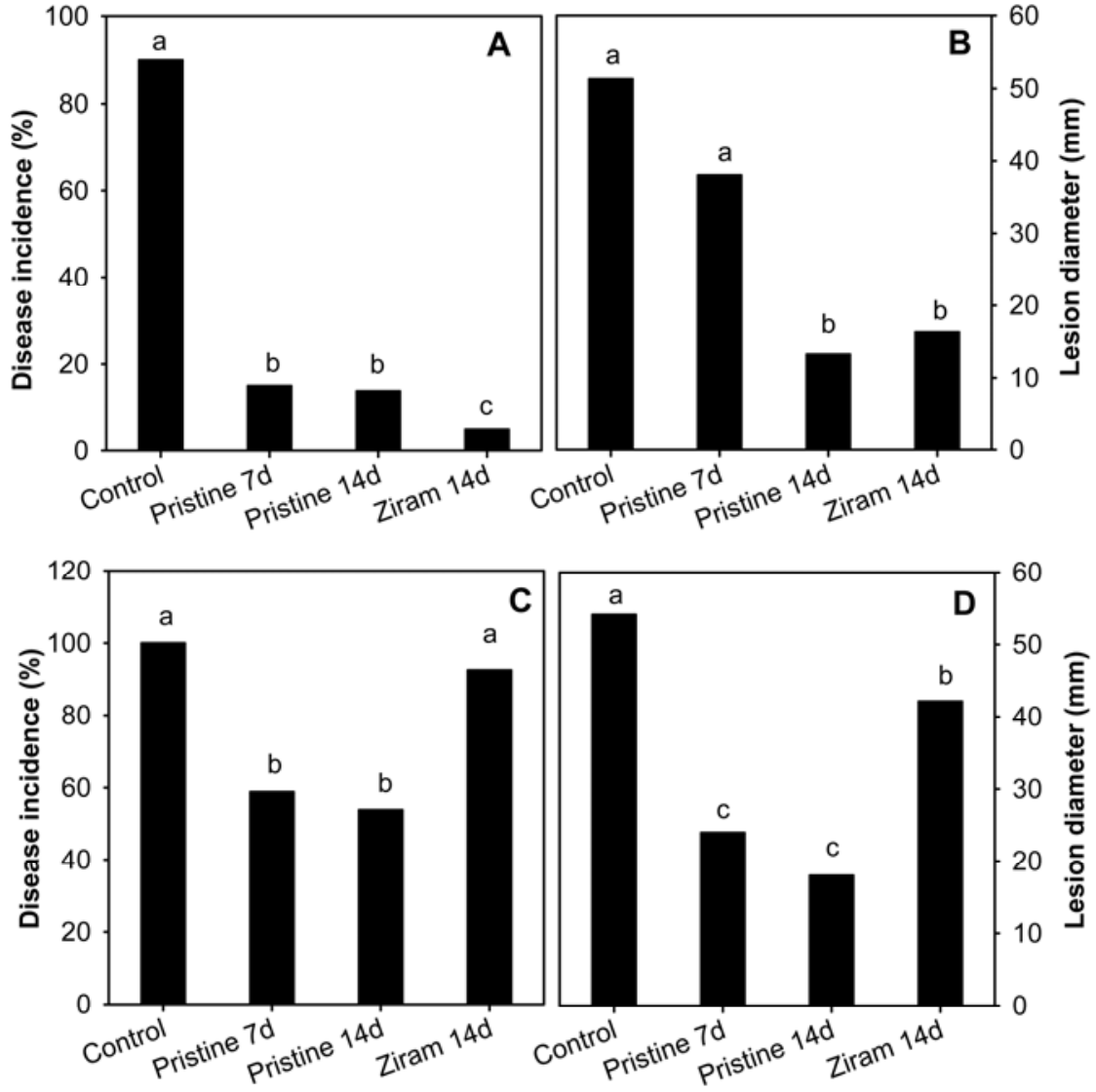

Fungicide treatments

Fig. 4. Effectiveness of Pristine, a premixed formulation of boscalid and pyraclostrobin, applied either 7 or 14 days before harvest and ziram applied 14 days before harvest in controlling gray mold (A and B) and blue mold (C and D) in stored Red Delicious apples in 2006. Fruit were wounded and inoculated with conidial suspensions of Botrytis cinerea or Penicillium expansum immediately after harvest and then stored at $0^{\circ} \mathrm{C}$ for 10 weeks, at which time decay was evaluated. Average lesion size within each replicate of each treatment was calculated among the decayed fruit only. Columns marked with the same letter are not significantly different at $k$-ratio $=100(P=0.05)$ according to the WallerDuncan $k$-ratio $t$ test.

tural, Human, and Natural Resource Sciences Agricultural Research Center, Project No. WNP00367, Washington State University, Pullman, WA 991646430, USA

\section{LITERATURE CITED}

1. Adaskaveg, J. E., Forster, H., and Sommer, N. F. 2002. Principles of postharvest pathology and management of decays of edible horticultural crops. Pages 163-195 in: Postharvest Technology of Horticultural Crops. 3rd ed. A. A. Kader, ed. University of California Agricultural and Natural Resources, Publ. 3311

2. Anonymous, 2003. Pristine ${ }^{\circledast}$ Fungicide. BASF Corporation. Research Triangle Park, NC, USA.

3. Avenot, H. H., Morgan, D. P., and Michailides, T. J. 2008. Resistance to pyraclostrobin, boscalid and multiple resistance to Pristine (pyraclostrobin+boscalid) fungicide in Alternaria alternata causing alternaria late blight of pistachio in California. Plant Pathol. 57:135140.

4. Bertolini, P., Guarnieri, A., and Venturi, P. 1995. Post-harvest fog treatment of apples: Deposition patterns and control of Phlyctaena vagabunda and superficial scald. Crop Prot.
14:345-348.

5. Blankenship, S. M., and Dole, J. M. 2003. 1Methylcyclopropene: A review. Postharv. Biol. Technol. 28:1-25.

6. Brent, K. J., and Hollomon, D. W. 1998. Fungicide Resistance: The Assessment of Risk. FRAC Monogr. No. 2, pp. 1-48. Global Crop Protection Federation, Brussels, Belgium.

7. Errampalli, D., Brubacher, N. R., and DeEll, J. R. 2006. Sensitivity of Penicillium expansum to diphenylamine and thiabendazole and postharvest control of blue mold with fludioxonil in 'McIntosh' apples. Postharv. Biol. Technol. 39:101-107.

8. Fan, X., Blankenship, S. M., and Mattheis, J. P. 1999. 1-Methylcyclopropene inhibits apple ripening. J. Am. Soc. Hortic. Sci. 124:690-695.

9. Fan, X., Mattheis, J. P., and Blankenship, S. M. 1999. Development of apple superficial scald, soft scald, core flush, and greasiness is reduced by MCP. J. Agric. Food Chem. 47:3063-3068.

10. Grasso, V., Palermo, S., Sierotzki, H. Garibaldi, A., and Gisi, U. 2006. Cytochrome tance to QoI fungicides in plant pathogens. Pest Manag. Sci. 62:465-472.

11. Kim, Y. K., and Xiao, C. L. 2008. Distribution $b$ gene structure and consequences for resis- and incidence of Sphaeropsis rot in apple in Washington State. Plant Dis. 92:940-946.

12. Li, H. X., and Xiao, C. L. 2008. Baseline sensitivities to fludioxonil and pyrimethanil in Penicillium expansum populations from apple in Washington State. Postharv. Biol. Technol. 47:239-245.

13. Meheriuk, M. 1993. CA storage conditions for apples, pears, and nashi. Pages 819-841 in: Proc. Int. Controlled Atmosphere Res. Conf., 6th.

14. Mitcham, E. J, and Mitchell, F. G. 2002 Postharvest handling systems: Pome fruits. Pages 333-344 in: Postharvest Technology of Horticultural Crops. 3rd ed. A. A. Kader, ed. University of California, Agriculture and Natural Resources, Publ. 3311.

15. Pscheidt, J. W., Kenyon, G., and Bassinette, J. P. 2005. Fungicides for control of apple scab and powdery mildew, 2004. Fungicide and Nematicide Tests 60:PF029.

16. Rosenberger, D. A. 1990. Blue mold. Pages 54-55 in: Compendium of Apple and Pear Diseases. A. L. Jones and H. S. Aldwinckle, eds. American Phytopathological Society, St. Paul, $\mathrm{MN}$.

17. Rosenberger, D. A. 1990. Gray mold. Pages 55-56 in: Compendium of Apple and Pear Diseases. A. L. Jones and H. S. Aldwinckle, ed. American Phytopathological Society, St. Paul, $\mathrm{MN}$.

18. Rosenberger, D. A., Meyer, F. W., and Christiana, R. W. 2005. Summer disease control with Captan, Flint, Pristine, Sovran, and Topsin M, 2004. Fungicide and Nematicide Tests 60:PF004.

19. Sholberg, P. L., Bedford, K. E., and Stokes, S. 2003. Effect of preharvest application of cyprodinil on postharvest decay of apple caused by Botrytis cinerea. Plant Dis. 87:10671071.

20. Sholberg, P. L., Bedford, K., and Stokes, S. 2005. Sensitivity of Penicillium spp. and Botrytis cinerea to pyrimethanil and its control of blue and grey mold of stored apples. Crop Prot. 24:127-134.

21. Smith, T. J., Dunley, J., Beers, E. H., Brunner J. F., Grove, G. G., Xiao, C. L., Elfving, D. C., Peryea, F., Parker, R., Mayer, D. F., Woodruff, R., Daniels, C., Maxwell, T., and Roberts, S. 2004. 2004 Crop Protection Guide for Tree Fruits in Washington. Washington State University Ext. Bull. (EB 0419).

22. Solel, Z., and Edgington, L. V. 1973. Transcuticular movement of fungicides. Phytopathology 63:505-510.

23. Spotts, R. A., Cervantes, L. A., and Mielke, E. A. 1999. Variability in postharvest decay among apple cultivars. Plant Dis. 83:1051-1054.

24. Sugar, D. 2002. Management of postharvest diseases. Chapter 9 in: Fruit Quality and its Biological Basis. M. Knee, ed. Sheffield Academic Press, Sheffield, UK

25. Sugar, D., Benbow, J. M., Powers, K. A., and Basile, S. R. 2003. Effect of sequential calcium, ziram, and yeast orchard sprays on postharvest decay of pear. Plant Dis. 87:12601262.

26. U.S. Environmental Protection Agency. 2006 Accomplishments under the Food Quality Protection Act (FQPA)-10th Anniversary of the Food Quality Protection Act. http://www.epa gov/pesticides/regulating/laws/fqpa/fqpa_accom plishments.htm. (accessed 17 April 2008).

27. Xiao, C. L., and Boal, R. J. 2005. Evaluation of fungicide programs for control of apple powdery mildew, 2004. Fungicide and Nematicide Tests 60:PF026. 